\title{
Article \\ Between Equality and the Right to Be Different-The Politicization of Concepts in the Fight against Discrimination Due to Sexual Orientation
}

\author{
Bruno Ferreira Costa (D)
}

Citation: Ferreira Costa, B. Between Equality and the Right to Be Different-The Politicization of Concepts in the Fight against Discrimination Due to Sexual Orientation. Sexes 2021, 2, 151-162. https://doi.org/10.3390/sexes2020013

Academic Editor: David L. Rowland

Received: 4 January 2021

Accepted: 31 March 2021

Published: 2 April 2021

Publisher's Note: MDPI stays neutral with regard to jurisdictional claims in published maps and institutional affiliations.

Copyright: (C) 2021 by the author. Licensee MDPI, Basel, Switzerland. This article is an open access article distributed under the terms and conditions of the Creative Commons Attribution (CC BY) license (https:// creativecommons.org/licenses/by/ $4.0 /)$.
Praxis-Centre of Philosophy, Politics and Culture, University of Beira Interior, 6201-001 Covilhã, Portugal; bdfc@ubi.pt; Tel.: +351-9-1334-6889

\begin{abstract}
The debate around the principle of equality and the theme of discrimination around sexual orientation has been one of the most relevant in the process of ensuring the spread of human rights. After ensuring a set of civil and political rights, several groups and social movements have warned political actors of the need to look at each citizen's individuality and guarantee through legislation and daily practices, respect for that individuality. This process is being conducted around the dichotomy between the concepts of equality and difference. It is from this analysis of the two concepts that we come across the theme of the rights of the lesbian, gay, bisexual, transvestite, transexual and transgender (LGBTQ+) community. With a qualitative approach, and while referring to the historical path of this theme, we review the central concepts in the promotion of equality and analyze the dichotomy between equality and difference. We ask, in an increasingly globalized world, does it make sense to point out difference as a mechanism for the defense of equality? Using semiotics, we approach the two central concepts and the political effort to normalize this theme to the public, using the Portuguese case (law and Non-Governmental organizations action) to characterize the central debate on equality and difference.
\end{abstract}

Keywords: equality; difference; sexual orientation; freedom; discrimination; individuality

\section{Introduction}

The analysis of equality issues leads to a natural and broader debate around the development of our society, while forcing the need to resort to a set of central concepts related to social rights and the values inherent to the relationships established between the members of a given community. The main debate is accompanied by the evolution of the attribution of a set of civil and political rights, mainly in the Western democracies, which constitutes a broad challenge in terms of the globalization of equality policies. This globalization of individual freedom represents a significant challenge for many societies. The pillars of this globalization are based on a set of international treaties and conventions, progressively adopted by states. The affirmation of the Universal Declaration of Human Rights represents a decisive step; however, both the interpretation of this declaration and the interpretations of the different national constitutions have led to a slow and controversial process in terms of the attribution of certain fundamental rights for the promotion of equality.

From a legal perspective, what does the principle of equality represent? To analyze the principles of equality, it is important to bear in mind the social and historical context, since the interpretation of the concepts varies from generation to generation, as well as according to the community under analysis. We can call equality being treated the "same way" and with the "same social dignity", but that is not enough to cover all dimensions of equality. If we consider what is expressed in the Universal Declaration of Human Rights (adopted by the United Nations General Assembly on 10 December 1948), it is clear that "all human beings are born free and equal in dignity and rights" (article 1) and that all citizens are entitled to these rights and freedom "without distinction of any 
kind, such as race, sex, language, religion, political or other opinion, national or social origin, property, birth or other status" (article 2) [1]. However, at the same time, one of the main challenges of social science research is related to the formulation of concepts and the problem of "traveling" [2], which leads to systematic questioning of the meanings of concepts and their applicability from a global perspective.

It makes sense, therefore, to question whether rights are transversal and universal or simply conjectural and localized as far as praxis is concerned. We will not address in this analysis the strength of Eurocentrism in relation to adopting certain concepts, or the historical approach considering the imposition of Western values on other parts of the world. However, it is important to mention that a set of values and perspectives did emanate from a Westernized vision; these concepts were imposed via imperialism and colonization [3]. The way such Western values are perceived and interpreted by other cultures corresponds to a defense and differentiation mechanism.

The path toward affirmation of ethnocentrism can correspond to an individual or collective attitude, being characterized by the way we look at another culture, mainly considering the environment and the social relations that surrounds us [4].

History plays a central role in establishing values and creating the conditions for the attribution of social and political rights. The concept of universal rights has spread in the context of globalization and is appealing to many, but at the same time, there is a set of barriers that prevent the transposition of values between societies. When facing this problem, we must bear in mind that the level of economic development of a society has a decisive influence on the affirmation of human rights.

To understand the composition of the core values of a specific community, it is important to highlight that the socialization process (at an individual level) can be decisive in the construction of the personal identity and the ability to intervene in discrimination scenarios. The emergence of new models of socialization, based on educational processes and interactions in social groups, has contributed to understanding the construction of individuals' social and personal identities [5]. We have a new way of looking at the world and perceiving the individual as an agent that transforms social reality. This ability is harnessed by the individual through a multiplicity of facets and social interactions-determinants for the analysis of society [6]. All cultural, social, political, and economic transformations are fundamental elements to understanding how social interactions have impacts on the way civil and political rights are defended.

The 20th century is marked by a set of important events for the affirmation of the current social order. In fact, the impacts of two major wars; the development of the decolonization process; the creation of international organizations, such as the United Nations and the European Union; the globalization of democratic regimes; and the affirmation of a set of individual freedoms have allowed for a consistent defense of the principle of equality. The defense of these fundamental rights goes beyond any constitutional (legal) plan or the legal order established by international organizations. Juridical actions and the law serve as a basis for the creation of a complete legal framework that protects individuality, but it is only the approval of society more broadly that validates the fight against all types of discrimination. This does not mean that the legal aspect is less relevant than social praxis, but the advent of new technologies and the strengthening of qualitative and field studies in the most diverse societies, leads to the growing need to go beyond normative aspects when approaching the issue of equality and the meaning of difference.

Before moving on to any quantitative, inferential, or correlational study, it is important to highlight the conceptualization process (there can be no correct research design without a delimitation of concepts). The conceptual delimitation corresponds to a determinant stage, provided for any study, to balance, with due clarity, the interpretation and meaning of each relevant research element [2]. Theoretical, philosophical, and applicable dimensions must be covered to understand all aspects of the concepts covered. The construction of concepts is carried out herein through those three dimensions; we address the concepts 
of "equality" and "difference" considering the global political debate on the rights of the lesbian, gay, bisexual, transvestite, transexual and transgender (LGBTQ+) community.

In this sense, it is important to consider the processes and the main actors of the socialization path when analyzing the impacts of the concepts on the issue of discrimination around sexual orientation. The focus of this article is not the analysis of biological characteristics adjacent to sexual orientation, but only on their impacts on established social networks - that is, we focus on sociology and the study of social constraints specifically. The analysis of sexuality can be carried out from a biological, cultural, or social point of view, and the present paper focuses on the last two lenses.

The present article is divided in two main parts: an initial overview of equality and difference, considering the conceptualization process and the analysis of civil and political rights; and a second part focusing on the impacts of these concepts on the politicization of the debate over LGBTQ+ rights, considering the Portuguese case. The analysis focuses on the evolution of concepts, based on the historical timeline of LGBTQ+ rights and the present debate over the individualization of society and the need to create common values and shared principles.

\section{Equality or Difference-The Impact of Concepts in the Fight Against Discrimination}

One of the essential criteria for addressing the dynamics of society is to go to the bases of the socialization process. Consider the different agents of socialization in the sexuality debate: age, friends and the media end up playing preponderant roles in the formation of the individual and his sexual experience, hence the importance of schooling that is didactic and knowledge-based. According to Spanier (1977) [7], sexual socialization involves five components of the developmental process: development of a sex-object preference; development of gender roles; development of gender identity; acquisition of sexual skills, knowledge, and values; and development of sexual attitudes.

The issue of sexual education is directly addressed by researchers, in terms of the evolution of the human body, the experience of sexuality, sexual orientation, and sexually transmitted diseases, although there is no broad consensus on the limits of this intervention in the development of individuals and in the socialization process (Table 1).

Table 1. Socialization Agents.

\begin{tabular}{cc}
\hline Levels of Socialization & Socialization Agents \\
\hline Primary Agents of Socialization & Family \\
\hline Secondary Agents of Socialization & School; Friends; Media; Religion \\
\hline Source: Berger and Luckmann, 1985 [8] (adapted). &
\end{tabular}

The central distinction among the socialization agents is related to the so-called "primary socialization" and "secondary socialization"- the first referring to the basic procedures of the individual's cultural life, namely, the rules, norms, and moral values shared by a given community and in the more restricted context of the family. Secondary socialization refers to a set of events and procedures related to one's experiences in a certain group or social category, often resulting from the individual's own decisions-for example, the results of practicing a religious ritual. In this context, it is possible to create a set of responsibilities attached to each socialization agent in the individual's training process, while always having in mind that the process could never be linearly deterministic, due to the contextual reality.

The construction of individuality results from a game of multiple influences. This principle intertwines with the existing socialization dynamics and the individual plays multiple social roles, some of which end up colliding both in terms of setting principles, and in terms of respect for principles, norms, or values acquired during the process of socialization. Therefore, when an individual acquires a set of behaviors, he does so according to the role that he is expected to play in society. 
In simple terms, "socialization refers to processes whereby naïve individuals are taught the skills, behavior patterns, values, and motivations need for competent functioning in the culture in the which the child is growing up" [9] (p. 3). In practical terms, socialization refers to a significative process of interaction between different members and groups of society, involving three dimensions: participation or involvement in politics; radical or conservative goals; and democratic or authoritarian actions [10].

This perspective allows one to verify the creation of bonds and relationships between the different elements of society, creating the opportunities for each individual to act and intervene in the transformation of the society. It is possible to find multiple definitions of socialization that reflect experiences and the respective cultural contexts; however, the focus of the present paper is on the analysis of the individual's participation in the construction of the societal rules.

The analysis of society resulting from the transformation of the twentieth century has been carried out based on a panoply of different theoretical concepts and perspectives. The choice of the central concepts is directly related to the objectives of the investigation and to the theoretical debate around the promotion of equality policies.

While it is true that in terms of legislation and the legal framework, much has been done to guarantee equality among citizens, there are still several issues related to situations of discrimination in the intergenerational and inter-societal debate. It is precisely in this debate that the conceptual issue emerges as a crucial pathway to understanding the issue of discrimination in relation to sexual orientation.

This dialectical view (equality versus difference) presupposes an opposition between the two concepts since it is not even possible to approach one concept without referring to the other. In this dynamic, it is important to mention that "we have the right to claim equality whenever difference makes us inferior, and we have the right to claim difference whenever equality de-characterizes us" [11] (p. 45). From this postulate, the systematic link between the two concepts is clear, as is the need to fit the criteria for classifying equality and difference according to the concrete situation under analysis.

In Figure 1, it is shown that any situation of equality naturally produces a differentiation between citizens and at the same time any differentiation could produce a path to mitigate these differences, although the result is not always what was intended. The registered differences generate a set of inputs in the system, which is the basis of the actions not only of political agents, but also of social agents in the defense of the individuality.
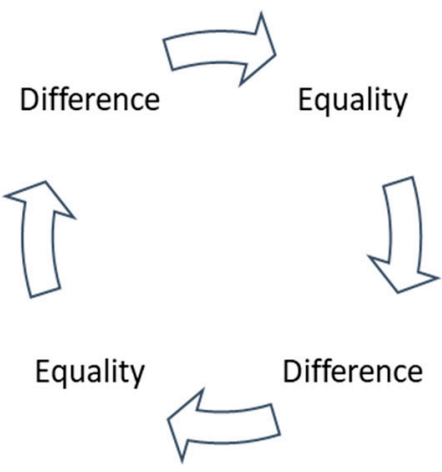

Figure 1. The Dynamics of Equality/Difference. Source: Author.

This articulation is in accordance with the vision of the political system and the innovative approach developed by David Easton (1976) [12], considering the analysis of the system based on the power relations. The systemic perspective refers to a constant retroactivity and multiple influences according to the outputs of each process. Each decision is influenced by several inputs (resources, limitations, and requirements) and produces a considerable number of outputs, with a retroactive effect (direct and indirect), allowing a renovation of the system. 
This debate is based on the concept of citizenship. According to Marshal's theoretical approach (1950) [13], we can identify four main characteristics involved in the perception of citizenship: the universality of citizenship (universal rights); the territorialization of citizenship (territorial delimitation); the plebiscitary principle of citizenship or the individuation of citizenship (direct link between the citizen and the state), and the state-national nature of citizenship (link between citizenship and the construction of the nation-state). This set of characteristics will be the basis of the considerations made about the framework of the actions to be developed to fight sexual discrimination. The choice of the adopted terminology is not incidental, as it justifies different paths in the defense of equal rights and opportunities. Finally, the main question is whether equality is possible considering the chronic and intrinsic differences between individuals. Another consideration is whether those differences are forcing political actors and society to act to generate equality.

It should be noted that the issue of citizenship is not sufficient to guarantee the same rights for the entire population, and it is natural to assume that all societies will contain within themselves a set of chronic and insusceptible inequalities to be solved. This is not a conformist attitude, but the acceptance of society's inability to solve all situations of inequality, which leads to another important question: is inequality inherent to society?

There is inevitable differentiation between human beings, and from these differences emerges a set of actions/reactions in the various social domains that fosters inequality between citizens. In sexual identify and orientation, the situation is the same; given the differences, citizens build a set of prejudices and develop a set of attitudes towards others. It is important to address the socialization process in the sexuality domain.

In this debate it is important to highlight the contribution of feminist theories to deconstructing the dichotomy between equality and difference. The studies that address the patriarchal dynamics of societies can be the basis of an analysis that pretends to deconstruct the pillars of inequality, in a context of male dominance, but this approach must be carried out in a multi-systemic context and with multiple influences [14]. In fact, women live in a problematic model of society based on a certain level of oppression; this oppression is a result of multilevel dynamics and influences [15]. This pattern requires an approach to the phenomenon of female empowerment in the most varied sectors of society, allowing the creation space to assure universal integration and impartial knowledge in the study of female representation [16,17].

In this wide-ranging debate on equality and difference, a third key concept is crucial to the present study: discrimination. In a schematic way, we can considerer discrimination as a form of "treating a person or particular group of people differently, especially in a worse way from the way in which you treat other people, because of their skin color, sex, sexuality" [18], or other characteristics. One of the key issues is related to LGBTQ+ discrimination, mainly the policies adopted to protect this social group and the effects observed. We are not talking about "special rights", but the assumption of civil and political rights to all citizens.

\section{Socialization and Sexuality-An Introductory Note}

Considering the socialization process and its relationship with the study of sexuality, there is direct action by all socialization agents, and identity is shaped by these interventions over one's entire life. The rapid development of societies, the affirmation of the media, and the adoption of legislation to ensure equality, all contribute to the present debate on sexuality issues.

Sexuality is no longer a taboo, or a subject addressed by minorities and in contexts without proper public expression. Nowadays it appears that it has ceased to be addressed in the closed and limited space of heterosexual spheres, and is instead expressed in all public spaces [19]. Sexual education appears to be a natural theme and is also a response to the need for the prevention of sexually transmitted diseases, as well as a response to the demands of youth population (who through the media easily access all the information regarding this subject). 
Media are the main source for young people to obtain information, and the impact of media in the socialization process of young people is one of the core elements to understanding the interactions among social groups [20]. Some authors and theories expose the large impacts of media on social interactions. This trend has completely transformed the existing social network, producing new mechanisms of action and new conflicts associated with a disruption between forms of socialization. In fact, in a plural environment and considering the roles of social agents, the debate about sexual experiences, attitudes, and preferences cannot be shaped or determined only by the dominant heteronormativity.

Nowadays, sexuality appears as a personal experience, fundamental in the construction of a citizen's identity. In this context, the sexual repertoire is wider, with a more diverse set of norms and trajectories of sexual life [21]. Human sexuality and its moral rules have been built on social changes, both at the level of institutions, and in the affirmation of new types of family. The era of freedom asserts itself in everyday practice. More liberty and a wider capacity to accept differences produce immediate effects in the affirmation of identities in opposition to traditional patterns. This acceptance is echoed in advertising campaigns carried out around sexual diversity, but also in the efforts of certain brands to ensure equality and seduce a new emerging market.

Our society is characterized by this trend: "The development of individual self-identity is inseparable from the parallel development of collective social identity" [22] (p. 133), and it is possible to find tensions between the construction of our identity and the message we try to pass to society. Our role could be simple, allowing that "all voluntary consumption carnes, either consciously or unconsciously, symbolic meanings; if the consumer has choices to consume, he or she will consume things that hold particular symbolic meanings" [22] (p. 134).

Taking into consideration the simple model of socialization, it is possible to identify trends and paths across multiple generations and societies. The main aspect in the present debate is the intersection of cultural variables, challenging the status quo of traditional analysis and Eurocentric concepts. The interpretation of identities must consider the multiple variants that integrate social interactions, thereby discussing identity issues in a multidimensional perspective [23]. Considering this view, sexuality is presented with a set of values and symbols that goes beyond the scientific approach. In fact, "sexuality plays an important role not only in legitimizing the order established between sexes, but also in representing the order of generations" [24] (p. 14); that is why different representations are necessary to study social, cultural, and ethnic groups.

It is in this framework of action that the present debate is postulated. The debate around these issues has always been limited to spaces of reduced intervention and public disclosure in a conservative and traditional society. This situation only experienced a reversal through the emergence of innumerable social movements, and a more open public agenda. From a systematic point of view, gender variations are explained by social-structural, social-interactive, cognitive-motivational, and biological influences, in a progressive process that integrates several dimensions, which are all related to the analysis of the gender assumption and gender discrimination [25].

\section{Experimental Section}

Methodological delimitation is crucial for academic production and the development of comparative mechanisms. This approach is based on a central premise: research should avoid focusing on a view that is too dependent on closed rules and unreliable for studying specific objects in social science domains, but at the same time, one must not take a path that disregards the importance of research methodology and techniques associated with scientific development. The main goal of the present work fits into several fields of research (from sociology, to education, psychology, and political science), but before adopting a prism and an appropriate methodology, it is important to define the concepts that mediate our work and our visions. The theoretical approach and the conceptualization process are the keys to establishing further empirical research. In fact, descriptive analysis "works according to systematic and objective procedures for describing message content" [26] (p. 37). 
This study focuses on a descriptive approach, with a qualitative basis, seeking to emphasize the interconnection of two central concepts in the analysis of the LGBTQ+ community: equality and difference (semiotic approach). The written linguistic approach allows the clarification of the use of these two concepts, in a process conducted in order justify the use of equality and difference justifications in political discussions. This analysis takes into inconsideration two important documents-the Universal Declaration of Human Rights and the International Covenant on Political and Civil Rights; and at the same time, the analysis of a specific case-Portugal. To assure the integration of the theoretical approach in a comprehensive domain, we focus on the Portuguese case in legal terms (the legislation approved) and considering the actions of civil society, using the example of ILGA Portugal (International Lesbian and Gay Association). For the latter purpose, it is important to mention the annual report of the organization regarding the rights of the LBGTQ+ community. Based on this classification, it is important to mention the historical framework for the defense of fundamental rights and freedom, as well as the political interpretations of these concepts. The main contribution is verified from an interpretative and theoretical point of view, at a time when scientific research implies a review of the bases on which research is settled.

\section{Results}

The emergence of more vague and abstract definitions has allowed a full conceptual framework; however, this strategy is not very useful for the purposes of this research. There is no research without conceptual and methodological delimitation, and any process of discrimination due to sexual orientation starts from the analysis and interpretation of two concepts: equality and difference.

\subsection{Equality}

In a first analysis, based on the Cambridge Dictionary definition, equality is the "right of different groups of people to have a similar social position and receive the same treatment" [27]—consider equality between the sexes, racial equality, and the role of government in applying equalities. The contribution of the legacy of Greek civilization to the defense of equality is evident, namely, in the typology of expressions that still prevail in our day. With a common denominator "isos" (meaning "equal") it is possible to carry out an exhaustive survey of sectors and areas where it is possible to apply the concept of equality.

In the scope of the present debate, equality is addressed as a key element for defending the same rights and the same dignity, in an increasingly global world, and based on the comparison of rights and ways of life. According to this scenario, we start from a generic assumption of differences associated with the context and way of life of each society. The defense of equality is intrinsically related to the attribution of a set of rights (civil, political, and social), based on the evolution of society and the demands of different social groups.

In a wider sense, we can defend the constitutionalizing of social rights the same way civil and political rights were introduced in legal documents. The main question is related to the capacity of political actors and governments to implement those rights. The focus on these three dimensions (civil, political, and social rights) is justified by the clear evidence for these principles in the "egalitarian liberal literature" [28] (p. 263), but in the mainstream debate some authors argue the importance of considering cultural and environment rights.

The implementation of the Universal Declaration of Human Rights in 1948 was a key moment in addressing the definition of equality. According to the United Nations' main document, "All are equal before the law and are entitled without any discrimination to equal protection of the law. [ ... ] All are entitled to equal protection against any discrimination in violation of this Declaration, and against any incitement to such discrimination" (article 7) [1]. The declaration makes the intended proposition clearer by addressing in arti- 
cle 16 that "men and women of full age, without any limitation due to race, nationality or religion, have the right to marry and to find a family" [1].

The legal assumptions that guide the multiple constitutions around the world are based on these premises, although the path of universalization of rights is, from the normative point of view, slow and gradual. The mere acceptance of a legal text and the transposition of these rules into national law does not represent an immediate adoption of the principle of equality. While it is true that more than three-quarters of the United Nations' member states are signatories of the International Covenant on Political and Civil Rights (adopted in 1976) [29], several studies demonstrated some discrepancies between the adoption of legal and international texts and changes in national political parties behavior. In a realistic approach, it may be optimistic to consider that integration into an international organization or the adoption of certain laws could have a direct impact on civil and political rights in a specific country [30].

\subsection{Difference}

For comparative purposes, according to the same source (Cambridge Dictionary), it is possible to define "difference" as "the way in which two or more things which you are comparing are not the same" [31]. All human beings are different, so the role model for an equal society must take into consideration this premise. The key is to understand the actions of the state or the legislators to assure that equality, because nothing can be done to eliminate the intrinsic differences of each citizen.

These differences are visible both in the national context and in the international scene, where social, cultural, and structural issues are necessary to model the differences between societies. The relationship between the unique aspects of each citizen and equality forces us to consider the importance of the semiotic approach. We face the affirmation of the dichotomy based on elements that make it possible to face equality or difference in relation to several aspects of social life. The two concepts are affirmed by the idea of opposition, that is, "the order of opposites" [24]. However, this is not a static interpretation; the ways we act, and our personalities are always evolutionary models. Differences are historical constructions, associated with each other's culture and way of life (we are the products of cultures). The semiotic approach allows for a full interpretation of the different concepts, but at the same time is an opportunity to understand the importance of certain laws to change individuals' mentality.

One of the main questions that arises from this debate is whether different treatment or special conditions can be applied in view of the conditions and characteristics of each citizen. In this analysis, we follow Barros' perspective: "Inequality and difference are not necessarily interdependent notions, although they can maintain well-defined relationships with certain social and political systems" [32] (p. 8).

In this analysis, the most relevant aspect is related to the intrinsic characteristics of each citizen. It is possible to promote more equality and to eliminate (or reduce) social and historical inequalities; however, it is not easy to present a strategy to eliminate differences between citizens, without going down a dangerous path of interference with the freedom of each citizen. This would represent the denial of humanity. Differences are intrinsic to humanity and to all societies. They are part of the construction of a unique social environment, which reflects the identity of a people.

\subsection{Equality and Difference in the Political Debate over Discrimination due to Sexual Orientation-The Portuguese Case}

The aim of this investigation is to address the politicization of concepts in the fight against discrimination due to sexual orientation. Due to the vast field of work, we focused the analysis on the verification of the LGBTQ+ community rights in Portugal, considering the realities of equality between citizens in this country. The path of affirming equality is followed by the political discourse adopted in each country, and the perspective chosen is crucial to verifying greater acceptance or rejection of the differences associated with sexual orientation. The Portuguese case is relevant in comparative terms due to three 
main reasons: the position of Portugal in international terms, considering the defense and adoption of laws promoting equality; the Catholic majority in Portugal—one of the highest rates of Catholicism in Europe, which could presuppose greater resistance to the adoption of legislation promoting equality; and the fact that Portugal is a recent democracy (comparatively)—as of 1974.

Sexual orientation is still a fracturing issue in several societies, but the "snowball effect" and the pressure from international organizations has contributed to a broader consensus related to the public and political discourse associated with sexual themes. Affirming the identities of individuals leads to a continuous process of accepting the differences. Part of this view results from the fact that "heterosexuality needs homosexuality for its own definition" [33] (p. 153), which produces an immediate opposition of interests, culminating in a historical view of homosexuality as a deviant behavior.

This process does not result from a sudden change in mentality, but rather from a long evolutionary process that is based on a broader set of social cleavages, namely, the emergence of a set of post-materialist values, focused on the movement that Inglehart called the "silent revolution" [34].

In view of the social imposition of heterosexuality as a "universal norm", queer theorists criticize compulsory heterosexuality, seeking to deconstruct the model and its main argument-that sexuality follows a natural course, in which sex, gender, sexual practices, and desire form a continuous and apparently coherent line [35].

According to the Annual Review on Human Rights of the LGBTQ+ community (in 54 countries), organized by ILGA-EUROPE [36], five criteria are addressed to analyze the protection of the LGBTQ+ community: respect for freedom of assembly, reunion, and expression; the legal recognition of gender identity; protection against hate speech or crimes; recognition of families; policies against discrimination and access to the right to asylum. According to that source, there have been increases of hate speech (official documents and political acts, and via social networks) and physical attacks against the LGBTQ+ community, in a transversal phenomenon in the countries under analysis.

The defense of gay rights is in line with the evolution of political regimes. The implementation, consolidation, and strengthening of democracies represents a solid basis for the implementation of legislation to assure the LGBTQ+ community a set of rights to ensure their integration and reduce the potential for discrimination. The evolution of LGBTQ+ studies is centered on wealth and religion issues, but interest is growing in analyzing the impacts of regimes on human rights, mainly in democracies, because gay rights are not universal in all democracies [37].

Considering the specific case of Portugal, it is important to address the main steps adopted to defend equality. Homosexual activity has been legal since 1982, only eight years after the revolution, and LGBT discrimination has been illegal since 2005. Homosexuals have been able to serve in the military since 1999, and there has been no legal blood donation discrimination since 2004. These steps were essential to assuring same-sex marriage (in 2010) and the same rights of adoption (in 2016), putting Portugal at the forefront of defending the rights of LGBTQ+ people [38].

According to this data, Portugal ranks fourth on international rankings. It was the sixth European country and the eight in the world to allow same-sex marriage, three years after a controversial referendum that decriminalized abortion (2007); in 2020, 24 countries have same-sex marriage granted by constitution [39]. The debate was always concentrated in Parliament, in a strategy adopted to assure the approval of these measures, even if public opinion showed some reservations on these issues, as was seen in the general poll conducted two years before on the approval of adoption rights by same-sex couples $(42 \%$ in favor, $38 \%$ against) [40].

One of the central organizations in this process was ILGA-Portugal, founded in 1995. ILGA-Portugal's action was essential to fight the idea that homosexuality was a deviant behavior. ILGA-Portugal stands not only for offering a range of services to the LGBTQ+ community, but also for interventions with civil society and political parties (pressure group 
and lobby), seeking to mitigate the points of discrimination, through a policy based on education and the promotion of equality. ILGA action was conducted through the analysis of several criteria, such as the respect for freedom of assembly, association, and expression; the legal recognition of gender identity; the protection against hate speech or crimes; legislation related to family rights and policies against discrimination and access to the right of asylum.

The Portuguese situation corresponds to a comparative advancement in terms of legislation; however, ILGA's annual report mentions some cases of discrimination. During the year of 2019, ILGA-Portugal received a total of 171 complaints, all related to situations resulting from prejudice, discrimination, and violence based on sexual orientation, gender identity, or sexual characteristics [41]. The debate in Portugal is centered in the issue of equality, instead of the promotion of differences, according to the principles emanated from the Portuguese constitution and the Equality national plans.

Based on these data, the importance of reinforcing the roles and actions of ILGAPortugal is highlighted, mainly because they act as a pressure/interest group with policy makers, as well as a strategy to reinforce the contacts with civil society through the organization of general/global activities, such as lectures and conferences. One of the key actions is related to support to "plural families", creating the conditions to integrate different family's formats.

This political debate moves along using ambiguous expressions, founded or grounded in official texts, often produced by international organizations, with a specific concern for the affirmation of equality among all citizens.

\section{Discussion}

The approach presented aims to provide a framework for the analysis of the central concepts in the debate around equality and around the struggles of LGBTQ+ movements, according to an exploratory conceptual and theoretical perspective. The definition of the concepts is the first element to consider in an interpretative study and the basis for further empirical research. The evolution of societies and the systematic differences between models of social organization correspond to the wider challenges of comparative analysis and verification of mechanisms to eliminate existing inequalities. In the present debate, it is important to state the dialogue between multiple scientific approaches and contributions and have in consideration the comparative aspect. In fact, several laws and procedures have been adopted according to international organization actions and official documents (United Nations; European Union) and according to the roles and actions of several nongovernmental organizations. The existence of a broader mechanism to promote equal rights is one of the paths that can be adopted to spread the LGBTQ+ protection across the world, namely, due to the approval of UN recommendations and the fulfillment of certain requirements for accessing work and cooperation platforms. The other path is represented by non-governmental organizations, such as ILGA, with an international impact on mediatizing social rights and cases of human rights violations.

Equality has become a controversial topic in public policies and in the differentiation of groups or social groups. Should the state be a regulator and the key actor to eliminating inequalities, and if so, to what extent? As the concept and the egalitarian principle is quite complex and subject to multiple interpretations, what is the common denominator to accept this intervention? [42]. Can the state ensure the principle of equality without considering the specific characteristics of each individual or group?

Differences are natural to human existence. Differences cannot be simply eliminated. This kind of intervention would result in a conditionality to existence, not acceptable in a liberal world. The evolution of civil, political, and social rights constitutes an essential historical order for the promotion of human rights and their application in a global context. The role of the concepts allows one to create a script for analyzing the functioning of the social organization and to understand the surrounding social interactions. In this debate, it is important to have no doubts about the defense of civil rights. Within the framework of 
social organization, chronic discrimination persists. The LGBTQ+ community has been the target of several attacks and the adoption of equal legislation does not eliminate all barriers from civic and political involvement, nor does it automatically create the same opportunities for the affirmation of individual rights. It is possible to identify homophobic attitudes and policies in every country, in every location [43].

Our conceptual analysis was complemented by the analysis of the actions of civil society in the implementation of preventive measures against discrimination. The examples of actions of non-governmental organizations revealed the margin for action in developed and democratic societies.

The debate around equality and difference must be based on theoretical and interpretive premises but go further with the reinforcement of empirical studies on the attitudes, values, and behaviors of the LGBTQ+ community and the whole community in the face of differences.

\section{Conclusions}

An individual's socialization around sexuality is an ongoing process, involving all actors and agents of socialization. In this regard, one's cultural, social, and political background plays a fundamental role, allowing a deeper analysis of the influences of these elements on the interactions inside each society and community. It is assumed that the interpretation of the concepts is influenced by several academic, historical, social, and contextual aspects. However, a unique trend has been identified in the official documents related to international organizations: the goal to defend equal treatment of all citizens. This is an ongoing process; many concepts about identity and sexual education need to be changed or at least adapted to new times and new social demands, from the perspective that considers the individual as the central agent of society. Societal changes and the progress achieved imply a similar process in all areas, and the inclusion of sexual education in the institutional mechanisms.

Prejudices and restrictions on debate will only limit knowledge about these important topics, leading to risky situations and maintenance of chronic discrimination. Political parties and political actors play important roles in decoding the concepts used in the scope of equality policies. In different contexts, legal mechanisms are presented as the first pillar of a mentality change, forcing societies to accept certain measures that promote equality, which was the case of Portugal (progressive legislation was adopted, shaping the mentality and acceptance behavior of the society).

The semiotic approach makes it possible to identify a natural opposition between the concepts of equality and difference, and the elimination of differences does not find a legal framework or basis considering the defense of human rights, so political action focuses on policies that promote equality. In the scope of LGBTQ+ rights, the historical path made remarkable progress in the second half of the twentieth century, with a more plural, more integrative, and more equality-based discourse, while considering cultural and social characteristics.

Funding: This research received no external funding.

Institutional Review Board Statement: Not applicable.

Informed Consent Statement: Not applicable.

Conflicts of Interest: The author declares no conflict of interest.

\section{References}

1. United Nations. Available online: https://www.un.org/en/universal-declaration-human-rights/index.html (accessed on 5 December 2020).

2. Sartori, G. Ensaios de Política Comparada; Livros Horizonte: Lisboa, Portugal, 2018.

3. Shohat, E.; Stam, R. Unthinking Eurocentrism. Multiculturalism and Media; Routledge: New York, NY, USA, 2014.

4. Sutherland, L. Ethnocentrism in a pluralistic society: A concept analysis. J. Transcult. Nurs. 2002, 13, 274-281. [CrossRef] [PubMed] 
5. Setton, M.G.J. A particularidade do processo de socialização contemporâneo. Tempo Soc. 2005, 17, 335-350. [CrossRef]

6. Giddens, A. As Consequências da Modernidade; Editora da UNESP: São Paulo, Brazil, 1991.

7. Spanier, G. Sexual socialization: A conceptual review. Int. J. Sociol. Fam. 1977, 7, 87-106.

8. Berger, P.; Luckmann, T. A Construção Social da Realidade; Vozes: Petrópolis, Brazil, 1985.

9. Grusec, J.; Hastings, P. Handbook of Socialization: Theory and Research, 2nd ed.; Guilford Publications: New York, NY, USA, 2008.

10. Hyman, H. Political Socialization; Free Press: New York, NY, USA, 1951.

11. Sousa Santos, B. A Construção Multicultural da Igualdade e da Diferença; Centro de Estudos Sociais: Coimbra, Portugal, 1999.

12. Easton, D. A Framework for Political Analysis; Prentice-Hall: Upper Saddle River, NJ, USA, 1965.

13. Marshall, T.H. Citizenship and Social Class: And Other Essays; Cambridge University Press: Cambridge, UK, 1950.

14. Scott, J. Deconstructing Equality-Versus-Difference: Or the Uses of Poststructuralist Theory of Feminism. Fem. Stud. 1988, 14, 254-270. [CrossRef]

15. Carastathis, A. The concept of intersectionality in Feminist Theory. Philos. Compass 2014, 9, 304-314. [CrossRef]

16. Disch, L.; Hawkesworth, M. Feminist Theory: Transforming the known world. In The Oxford Handbook of Feminist Theory; Disch, L., Hawkesworth, M., Eds.; Oxford University Press: Oxford, UK, 2016.

17. Goldenberg, M.J. The Problem of Exclusion in Feminist Theory and Politics: A Metaphysical Investigation into Constructing a Category of 'Woman'. J. Gend. Stud. 2007, 16, 139-153. [CrossRef]

18. Cambridge Dictionary. Available online: https://dictionary.cambridge.org/dictionary/english/discrimination (accessed on 21 December 2020).

19. Reiss, I.L. An End to Shame-Shaping Our Next Sexual Revolution; Prometheus Books: Buffalo, NY, USA, 1990.

20. Ward, L.M. Understanding the role of entertainment media in the sexual socialization of American youth: A review of empirical research. Dev. Rev. 2002, 23, 347-388. [CrossRef]

21. Vilar, R. A Educação sexual faz sentido no actual contexto de mudança? Educ. Sex. Rede 2005, 1, 8-14.

22. Elliot, R.; Wattanasuwan, K. Brands as symbolic resources for the construction of identity. Int. J. Advert. 1998, 17, 131-144. [CrossRef]

23. Fukuyama, M.A.; Ferguson, A.D. Lesbian, gay and bisexual people of color: Understanding cultural complexity and managing multiple oppressions. In Handbook of Counseling and Psychotherapy with Lesbian, Gay, and Bisexual Clients; Perez, M., DeBord, A., Biescheke, K.J., Eds.; American Psychological Association: Washington, DC, USA, 2000; pp. 81-105.

24. Bozon, M. Sociologie de la Sexualité; Nathan/VUEF: Paris, France, 2002.

25. Leaper, C.; Friedman, C.K. The Socialization of Gender. In Handbook of Socialization: Theory and Research; Grusec, J.E., Hastings, P.D., Eds.; The Guilford Press: New York, NY, USA, 2007.

26. Bardin, L. Análise de Conteúdo; Edições 70: Lisboa, Portugal, 2008.

27. Cambridge Dictionary. Available online: https:/ / dictionary.cambridge.org/dictionary/english/equality (accessed on 22 December 2020).

28. Fabre, C. Constitutionalizing Social Rights. J. Political Philos. 1998, 6, 263-284. [CrossRef]

29. International Covenant on Civil and Political Rights. Available online: https://www.ohchr.org/EN/ProfessionalInterest/Pages/ CCPR.aspx (accessed on 22 December 2020).

30. Keith, L.C. The United Nations International Covenant on Civil and Political Rights: Does it Make a Difference in Human Rights Behavior? J. Peace Res. 1999, 36, 95-188. [CrossRef]

31. Cambridge Dictionary. Available online: https://dictionary.cambridge.org/dictionary/english/difference (accessed on 22 December 2020).

32. Barros, J.A. Igualdade e diferença: Uma discussão conceitual mediada pelo contraponto das desigualdades. Rev. Bras. Educ. 2018, 23. [CrossRef]

33. Miskolci, R. A teoria queer e a sociologia: O desafio de uma analítica da normalização. Sociologias 2009, 21, 150-182. [CrossRef]

34. Inglehart, R. The Silent Revolution: Changing Values and Political Styles among Western Publics; Princeton University Press: Princeton, NJ, USA, 1977.

35. Butler, J. Problemas de Género: Feminismo e Subversão da Identidade; Editora Civilização Brasileira: Rio de Janeiro, Brazil, 2003.

36. Annual Review of the Human Rights Situation of Lesbian, Gay Bisexual, Trans and Intersex People in Europe and Central Asia. Available online: https:/ / www.ilga-europe.org/sites/default/files/Annual\%20Review\%202020.pdf (accessed on 18 December 2020).

37. Encarnación, O.G. Gay Rights: Why democracy matters. J. Democr. 2014, 25, 90-104. [CrossRef]

38. Equaldex Data Base. Available online: https://www.equaldex.com/compare/portugal (accessed on 20 February 2021).

39. LGBT Rights by Country 2021. Available online: https://worldpopulationreview.com/country-rankings/lgbt-rights-by-country (accessed on 20 February 2021).

40. Maioria dos Portugueses Votaria a Favor da Adoção por Casais Homossexuais. Available online: https://sicnoticias.pt/pais/20 14-02-14-Maioria-dos-portugueses-votaria-a-favor-da-adocao-por-casais-homossexuais (accessed on 20 February 2021).

41. ILGA Annual Report. Available online: https://www.ilga-europe.org/sites/default/files/2020/portugal.pdf (accessed on 20 February 2021).

42. Armstrong, C. Complex equality: Beyond equality and difference. Fem. Theory 2002, 3, 67-82. [CrossRef]

43. Badgett, M.V.L.; Frank, J. Sexual orientation discrimination. In The Global Gap. Institutions, Markets and, Social Change; Badgett, M.V.L., Frank, J., Eds.; Routledge: New York, NY, USA, 2007. 